\title{
Research on the Comprehensive Strength Evaluation for Universities based on the Fuzzy TOPSIS Method
}

\author{
https://doi.org/10.3991/ijet.v12.i08.7136 \\ Fuqin Yue \\ Xi'an International University, Xi'an, Shaanxi, China \\ yuefuqine $126 . \mathrm{com}$
}

\begin{abstract}
In recent years, the scale of enrollment in colleges and universities continues to expand. The private colleges are also springing up. The comprehensive strength of each university is uneven. Evaluating the comprehensive strength for the colleges is not only to provide the reference for the majority students' parents, but also to promote the continue development for the comprehensive strength of the colleges. In this paper, in order to make the better evaluation of the comprehensive strength for the colleges, we combine the fuzzy theory with the TOPSIS method and propose an improved fuzzy TOPSIS method. Then, we use the method to evaluate the comprehensive strength for the college. The experimental results demonstrate the reliability and the validity of the method.
\end{abstract}

Keywords-Fuzzy theory, Comprehensive strength, Evaluation

\section{Introduction}

In 1983 year, the United States famous news magazine of "American news and World Report" released the world's first university rankings. And it opened the prologue of the world's college rankings. In 1987 year, Jiang Guohua profess who is the founder of China's scientific metrology published the first college rankings for Chinese colleges. It was the studied content for the world's scholars to rank and evaluate the colleges. It had the profound and broad sense.

Evelyn Bergsmann and other scholars evaluated the competence-based teaching in higher education institutions [1]. The author provided a more comprehensive evaluation concept that contributed to sustainable improvement of competence-based teaching in higher education institutions. The evaluation concept was composed of three stages. They were the evaluated ability, the practical obtained ability for the students and the specific link of teaching. The main evaluation objects for this paper were the competence-based curriculum in higher education. Ren-Zhong Peng, Wei-Ping Wu, Wei-Wei Fan assessed Chinese college students' intercultural competence based on the theories of intercultural competence and the method of fuzzy comprehensive evaluation [2]. In the process of constructing the model, the author adopted the viewpoint of the experts to measure the importance of each index of Chinese college students' intercultural competence. The comparison of the results suggested that the fuzzy 
comprehensive evaluation model can be used effectively to assess Chinese college students' intercultural competence. Yin Zhiming studied the comprehensive evaluation index system for Chinese universities [3]. The author began from the produce of evaluating the train at home and aboard. Firstly, the author reviewed the evaluation for the universities. Then, the author discussed the principle for setting the index from the single index and the index system and made the empirical study for the colleges' evaluation. Finally, the author compared the results with the evaluation report of the Chinese comprehensive evaluation. $\mathrm{Xu}$ Min studied and evaluated university knowledge management [4]. The author used the systematic analysis method to comb the college knowledge management content and the evaluated structure from up to down. Then, the author constructed the dimension model of the college knowledge management with the existing theoretical model. The paper used the multi-level grey correlation evaluation method to evaluate comprehensively the knowledge management for 61 universities. Then we got the relative evaluation rankings. Finally, the paper combined with the actual situation of one college and used the fuzzy comprehensive evaluation method to get the absolute evaluation score of the knowledge management for the college. Li Bifang evaluated the college comprehensive strength according to the fuzzy evaluation method of the set-valued iteration [5]. Huang Qingsun evaluated and analyzed the comprehensive strength status of the colleges in Guang Xi. And he studied the stratagem [6]. According to the characteristics of the evaluation in colleges, Wang Xiaoyan determined the fuzzy evaluation matrix and the weight coefficient. And he applied the fuzzy comprehensive evaluation method to study the college teaching evaluation method [7].

The fuzzy theory was developed on the basis of the fuzzy set theory, which was founded in 1965 by L.A.Zadeh, a professor at California University. The basic idea of the fuzzy theory was to accept the fact that the fuzzy phenomenon existed. He took the uncertain objects as the research object. It mainly contented the fuzzy mathematics [8-9], fuzzy logic [10-11], fuzzy system [12-13], fuzzy control [14-15] and fuzzy decision [16-17]. TOPSIS method is short for technique for order preference by similarity to ideal solution. It was the common method for the system engineering. TOPSIS method is one of the most evaluation methods. It has applied to the fields, such as the economy [18-19], management [20-21], agriculture [22-23] and industrial [24-25].

In this paper, in order to make a better evaluation for the college comprehensive strength, we combine the fuzzy theory with TOPSIS method and propose the improved fuzzy TOPSIS method. The structure of this paper is as follows. The first part is the introduction. In this part, we mainly introduce the status of the college evaluation. The second part is the TOPSIS method. In this part, we mainly introduce the basic step of the TOPSIS method. The third step is the improved fuzzy TOPSIS method. In the third part, we propose an improved fuzzy TOPSIS method. The fourth part is the experiment and the last part is the conclusion. 


\section{TOPSIS method}

TOPSIS method was firstly proposed by Hwang and Yoon in 1981. Due to the complexity of the real decision problems, TOPSIS method was used to deal with the decision problems in different situations, such as fuzzy decision problem and group decision problem. The basic idea of TOPSIS method is to make the ideal point and the negative ideal point as the reference and adopt the Euclidean distance to measure the distance between any feasible scheme and the ideal point. The basis for evaluating the merits of each scheme is to approach the ideal point and to be far away from the negative ideal point. The steps of TOPSIS method are as follows.

The first step is to standard the decision matrix $X=\left(x_{i j}\right)_{m \times n}$. And we get the standardized decision matrix $Y=\left(y_{i j}\right)_{m \times n}$.

$$
y_{i j}=\frac{x_{i j}}{\sqrt{\sum_{i=1}^{m} x_{i j}^{2}}},(i=1,2, \mathrm{~L}, m ; j=1,2, \mathrm{~L}, n)
$$

The second step is to construct the weighted standardization matrix $Z=\left(z_{i j}\right)_{m \times n}$.

$$
z_{i j}=w_{j} y_{i j},(i=1,2, \mathrm{~L}, m ; j=1,2, \mathrm{~L}, n)
$$

The third step is to determine the positive ideal solution $A^{+}$and the negative ideal solution $A^{-}$for the multi attribute decision.

$$
\begin{aligned}
A^{+} & =\left(z_{1}^{+}, z_{2}^{+}, \mathrm{L}, z_{n}^{+}\right) \\
& =\left\{\left(\max _{i} z_{i j} \mid j \in I\right),\left(\min _{i} z_{i j} \mid j \in J\right)\right\} \\
A^{-} & =\left(z_{1}^{-}, z_{2}^{-}, \mathrm{L}, z_{n}^{-}\right) \\
& =\left\{\left(\min _{i} z_{i j} \mid j \in I\right),\left(\max _{i} z_{i j} \mid j \in J\right)\right\}
\end{aligned}
$$

Where, $I$ is the set of the income property index. And $J$ is the set of the cost property index.

The fourth step is to calculate the distance $d_{i}^{+}$between each scheme $A_{i}, \mathrm{i}=1,2, \ldots$, $\mathrm{m}$ and the positive ideal solution. The $d_{i}$ is the distance between each scheme $A_{i}, \mathrm{i}=1$, $2, \ldots, \mathrm{m}$ and the negative ideal solution.

$$
\begin{aligned}
& d_{i}^{+}=\left\|\mathrm{z}_{i}-A^{+}\right\|=\sqrt{\sum_{j=1}^{n}\left(z_{i j}-z_{j}^{+}\right)^{2}},(i=1,2, \mathrm{~L}, m) \\
& d_{i}^{-}=\left\|\mathrm{z}_{i}-A^{-}\right\|=\sqrt{\sum_{j=1}^{n}\left(z_{i j}-z_{j}^{-}\right)^{2}},(i=1,2, \mathrm{~L}, m)
\end{aligned}
$$

The fifth step is to calculate the relative degree $C_{i}^{+}=\frac{d_{i}^{-}}{d_{i}^{+}+d_{i}^{-}}$of each scheme.

Obviously, $0 \leq C_{I}^{+} \leq 1, i=1,2, \ldots, m$. The relative degree of the positive ideal point is 1. And the relative degree of the negative ideal point is 0 .

The sixth step is to use the value of the relative degree to rank the schemes. 


\section{The improved fuzzy TOPSIS method}

In this paper, we divide the fitness value range into five grades. They are $S=\left\{\operatorname{poor}\left(s_{1}\right)\right.$, general $\left(s_{2}\right), \operatorname{good}\left(s_{3}\right)$, excellent $\left.\left(s_{4}\right)\right\}$.

We assume that $A_{i}$ is the evaluated scheme, $i=1,2, \ldots, m . D_{k}$ is the evaluated expert. And the attribute weight is $\lambda_{k}$. $\lambda_{k} \in[0,1]$ and $\sum_{k=1}^{t} \lambda_{k}=1, \mathrm{k}=1,2, . ., \mathrm{t} . C_{j}$ is the evaluated index. The weight is $w_{j} . w_{j} \in[0,1]$ and $\sum_{j=1}^{n} w_{j}=1, \mathrm{j}=1,2, \ldots, \mathrm{n}$. The attribute value of the evaluated index $C_{j}$ is $x_{i j}^{k}$ that the expert $D_{k}$ evaluates for the scheme $A_{i}$. Then, it constitutes the language fuzzy decision matrix $R^{(k)}=\left(r_{i j}{ }^{(k)}\right)_{m \times n}$.

Define 1: We assume that $S=\left\{s_{0}, s_{1}, \ldots, s_{g}\right\}$ is a language evaluation set. $\beta \in[0,1]$ is the real number which is accepted by one assembly method for the language evaluation set. The binary semantic which is corresponding to $\beta$ can be expressed by the following function.

$$
\begin{gathered}
\Delta:[0,1] \rightarrow S \times[-1 / 2 g, 1 / 2 g] \\
\Delta(\beta)=\left(s_{i}, a\right) \\
\text { Where, } \begin{array}{rr}
s_{i}, & i=\operatorname{round}(\beta * g) \\
a=\beta-i / g, & a=[-1 / 2 g, 1 / 2 g]
\end{array}
\end{gathered}
$$

Define 2: We assume that $S=\left\{s_{0}, s_{1}, \ldots, s_{g}\right\}$ is a language evaluation set. $\left(s_{k}, a\right)$ is a dual language. Then, it exists the inverse function. The inverse function can transfer the Binary semantic to the corresponding numerical.

$$
\begin{gathered}
\Delta^{-1}: S \times[-1 / 2 g, 1 / 2 g] \rightarrow[0,1] \\
\Delta^{-1}:\left(s_{k}, a\right)=i / g+a=\beta
\end{gathered}
$$

Define 3: If $X=\left\{\left(r_{1}, a_{1}\right),\left(r_{2}, a_{2}\right), \ldots,\left(r_{n}, a_{n}\right)\right\}$ is a set of binary semantic set. $W=\left(w_{l}\right.$, $\left.w_{2}, \ldots, w_{n}\right)^{T}$ is the corresponding weight vector. Then, the weighted average operator of the binary semantic is as follows.

$$
T W A(X)=\Delta\left(\sum_{i=1}^{n} \Delta^{-1}\left(r_{i}, a_{i}\right) w_{i}\right)=\Delta\left(\sum_{i=1}^{n} \beta_{i} w_{i}\right)
$$

Define 4: We assume that $\left(s_{k}, \sigma_{k}\right)$ and $\left(s_{i}, \sigma_{i}\right)$ are two binary semantic.

(1) If $k>l$

$$
\left(s_{k}, \sigma_{k}\right)>\left(s_{i}, \sigma_{i}\right)
$$

(2) If $k=l$

$$
\begin{array}{r}
\sigma_{k}=\sigma_{i},\left(s_{k}, \sigma_{k}\right)=\left(s_{i}, \sigma_{i}\right) \\
\sigma_{k}>\sigma_{i},\left(s_{k}, \sigma_{k}\right)>\left(s_{i}, \sigma_{i}\right) \\
\sigma_{k}<\sigma_{i},\left(s_{k}, \sigma_{k}\right)<\left(s_{i}, \sigma_{i}\right)
\end{array}
$$

For the benefit index and the cost index, in order to eliminate the influence of different dimensional attribute value on the decision results, we need to deal with them for the unification. The benefit index for the language type is to use the inverse operator of the natural language evaluation set $S=\left\{s_{0}, s_{1}, \ldots, s_{g}\right\}$. It transfers the correspond- 
ing benefit index to the cost index. On the contrary, it use the inverse operator to transfer the cost index to the benefit index. For the calculation convenience, we give the following define. It unifies the indexes for the transition between the cost index and the benefit index.

Define 5: We assume that $S=\left\{s_{0}, s_{1}, \ldots, s_{g}\right\}$ is a language evaluation set. The formula that the cost index transfers to the benefit index which is based on the two tuple linguistic inverse operator $\mathrm{Neg}$ is as follows.

$$
\operatorname{Neg}\left(s_{k}, \sigma_{k}\right)=\Delta\left(1-\left(\Delta^{1}\left(s_{k}, \sigma_{k}\right)\right)\right)
$$

Then, we use the new weight distribution method. That is, we use the dynamic weight distribution method to calculate the weight of each index. The steps are as follows.

The first step is as follows. We make each factor as the measure standard. And we put the priority factor into the right of the factor. And we put the unimportant factor into the left of the factor. It is easy for the design staff to achieve the process.

Table 1. The importance of the factors

\begin{tabular}{|l|l|l|}
\hline \multicolumn{1}{|c|}{ Left } & \multicolumn{1}{c|}{ measure standard } & \multicolumn{1}{c|}{ Right } \\
\hline$S_{3}, S_{4}$ & $S_{1}$ & $S_{2}$ \\
\hline$S_{1}, S_{3}, S_{4}$ & $S_{2}$ & \\
\hline & $S_{3}$ & $S_{1}, S_{2}, S_{4}$ \\
\hline$S_{3}$ & $S_{4}$ & $S_{1}, S_{2}$ \\
\hline
\end{tabular}

The second step is to statistic the compared results.

$$
\begin{aligned}
& N_{L-s_{1}}=1, N_{L-s_{2}}=0, N_{L-s_{3}}=3, N_{L-s_{4}}=2 ; \\
& N_{R-s_{1}}=2, N_{R-s_{2}}=3, N_{R-s_{3}}=0, N_{R-s_{4}}=1
\end{aligned}
$$

Where, $N_{L-s i}$ is the number that the factor $S_{i}$ in the left. $N_{R-s i}$ is the number that the factor $S_{i}$ in the right. That is the importance.

$$
\begin{aligned}
& N_{s_{1}}=N_{R-s_{1}}-N_{L-s_{1}}=2-1=1 \\
& N_{s_{2}}=N_{R-s_{2}}-N_{L-s_{2}}=3-0=3 \\
& N_{s_{3}}=N_{R-s_{3}}-N_{L-s_{3}}=0-3=-3 \\
& N_{s_{4}}=N_{R-s_{4}}-N_{L-s_{4}}=1-2=-1
\end{aligned}
$$

The third step is to calculate the most important factor $S_{2}$ and the least important factor $S_{3}$. According to the 1-9 ratio scaling method, the design staff gives the important degree $b_{23}(1<b \leq 9)$ of $\mathrm{U} 3$. Therefore, we can divide the numerical scale $\left[N s_{3}\right.$, $\left.N s_{2}\right]=[-3,3]$ into $b_{32}-1$. Each node represents a scale. We assume that $b_{32}=5$. Then we can get the following table.

Table 2. scale comparison table

\begin{tabular}{|c|c|c|c|c|c|}
\hline Numerical solution point & -3 & -1.5 & 0 & 1.5 & 3 \\
\hline Scaling & 1 & 2 & 3 & 4 & 5 \\
\hline
\end{tabular}


For other $b_{3 i}$, we determine is according to the nearest principle. $N_{3 i}$ is near to which numerical node, $b_{3 i}$ will take that corresponding scaling. The intermediate value takes the right node. Then we can get $b_{31}=4, b_{32}=5, b_{33}=4, b_{34}=3$. Then, the relative importance of other factors can be calculated by the scaling of the least important factor for each factor. The calculation method is $b_{j i}=1+\left(b_{3 i}-b_{3 j}\right), b_{3 i} \geq b_{3 j}$. Where, $b_{3 i} \geq b_{3 j}$. The calculation results are as follows.

Table 3. Factor scaling value table

\begin{tabular}{|l|c|c|c|c|}
\hline \multicolumn{1}{|c|}{ Attribute } & $\boldsymbol{S}_{\boldsymbol{I}}$ & $\boldsymbol{S}_{2}$ & $\boldsymbol{S}_{3}$ & $\boldsymbol{S}_{4}$ \\
\hline$S_{1}$ & 1 & 2 & $1 / 4$ & $1 / 2$ \\
\hline$S_{2}$ & $1 / 2$ & 1 & $1 / 5$ & 3 \\
\hline$S_{3}$ & 4 & 5 & 1 & 3 \\
\hline$S_{4}$ & 2 & $1 / 3$ & $1 / 3$ & 1 \\
\hline
\end{tabular}

The fourth step is to calculate the feature vector of the matrix. Then we make the normalized processing and get the weight values.

We apply the improved fuzzy TOPSIS method to evaluate. The specific step is as follows.

The first step is to use the binary semantic inverse operator to transfer the cost index to the benefit index.

The second step is to transfer the language evaluation matrix $R_{k}=\left(r_{i j}^{(k)}\right)_{m \times n}$ to the binary semantic evaluation matrix $R_{k}^{\prime}=\left(r_{i j}^{(k)}, 0\right)_{m \times n}$ for the scheme.

The third step is to use TWA operator to build up $R_{k}^{\prime}$ into the binary semantic evaluation matrix $R=\left(r_{i j}, a_{i j}\right)_{m \times n}$.

$$
\begin{aligned}
\left(r_{i j}, a_{i j}\right) & =T W A\left(\left(r_{i j}^{(1)}, 0\right),\left(r_{i j}^{(2)}, 0\right), \mathrm{L},\left(r_{i j}^{(k)}, 0\right)\right) \\
& =\Delta\left(\sum_{k=1}^{t}\left(\Delta^{-1}\left(r_{i j}^{(k)}, 0\right) \lambda_{k}\right)\right)
\end{aligned}
$$

The fourth step is to determine the binary semantic positive ideal solution $\mathrm{O}^{+}$and the binary semantic positive ideal solution $O^{-}$.

$$
\begin{aligned}
O^{+} & =\left(r^{+}, a^{+}\right) \\
& =\left(\left(r_{1}^{+}, a_{1}^{+}\right),\left(r_{2}^{+}, a_{2}^{+}\right),\left(r_{3}^{+}, a_{3}^{+}\right), \mathrm{L},\left(r_{n}^{+}, a_{n}^{+}\right)\right) \\
O^{-} & =\left(r^{-}, a^{-}\right) \\
& =\left(\left(r_{1}^{-}, a_{1}^{-}\right),\left(r_{2}^{-}, a_{2}^{-}\right),\left(r_{3}^{-}, a_{3}^{-}\right), \mathrm{L},\left(r_{n}^{-}, a_{n}^{-}\right)\right)
\end{aligned}
$$

Where

$$
\begin{aligned}
& \left(r_{j}^{+}, a_{j}^{+}\right)=\max _{i}\left\{\left(r_{i j}, a_{i j}\right)\right\}, j=1,2, \mathrm{~L}, n \\
& \left(r_{j}^{-}, a_{j}^{-}\right)=\min _{i}\left\{\left(r_{i j}, a_{i j}\right)\right\}, j=1,2, \mathrm{~L}, n
\end{aligned}
$$

The fifth step is to calculate the weight $w=\left(w_{1}, w_{2}, \ldots, w_{n}\right)^{T}$ of each attribute.

The sixth step is to calculate the distance from each scheme to the positive solution and the negative solution. 


$$
\begin{aligned}
& \left(d_{i}^{+}, a_{i}^{+}\right)=\Delta\left(\sum_{j=1}^{n}\left(\left|\Delta^{-1}\left(r_{i j}, a_{i j}\right)-\Delta^{-1}\left(r_{j}^{+}, a_{j}^{+}\right)\right| w_{j}\right)\right) \\
& \left(d_{i}^{-}, a_{i}^{-}\right)=\Delta\left(\sum_{j=1}^{n}\left(\left|\Delta^{-1}\left(r_{i j}, a_{i j}\right)-\Delta^{-1}\left(r_{j}^{-}, a_{j}^{-}\right)\right| w_{j}\right)\right)
\end{aligned}
$$

The seventh step is to calculate the relative closeness degree from each scheme to the positive solution.

$$
\left(d_{i}, a_{i}\right)=\frac{\Delta\left(\Delta^{-1}\left(d_{i}^{-}, a_{i}^{-}\right)\right.}{\left.\left(\Delta^{-1}\left(d_{i}^{-}, a_{i}^{-}\right)+\Delta^{-1}\left(d_{i}^{+}, a_{i}^{+}\right)\right)\right)}
$$

The eighth step is to get the ranking results according to the relative closeness degree for the scheme.

\section{$4 \quad$ Experiment}

Before we evaluate the college strength, we need to select the evaluated indexes. We select these indexes from five aspects. The evaluated indexes are as follows.

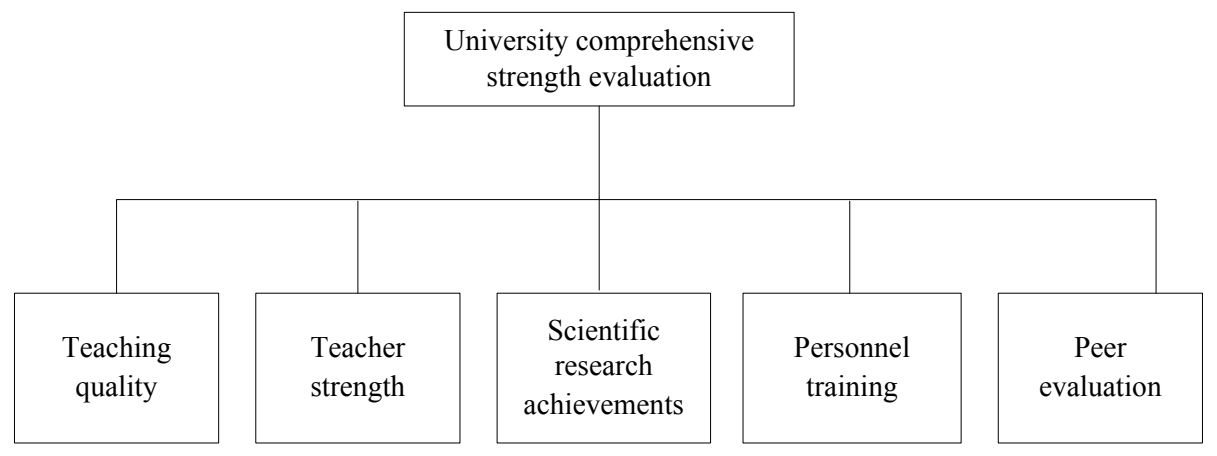

Fig. 1. College comprehensive evaluation system

We evaluate comprehensively for five colleges. Scheme evaluation table are as follows.

Table 4. Scheme evaluation table

\begin{tabular}{|l|c|c|c|c|c|}
\hline Scheme & $\boldsymbol{C}_{\boldsymbol{I}}$ & $\boldsymbol{C}_{\boldsymbol{2}}$ & $\boldsymbol{C}_{3}$ & $\boldsymbol{C}_{4}$ & $\boldsymbol{C}_{5}$ \\
\hline$A_{1}$ & $\left(s_{4}, 0.16\right)$ & $\left(s_{3}, 0.00\right)$ & $\left(s_{2}, 0.00\right)$ & $\left(s_{5}, 0.16\right)$ & $\left(s_{5}, 0.08\right)$ \\
\hline$A_{2}$ & $\left(s_{5}, 0.08\right)$ & $\left(s_{5}, 0.08\right)$ & $\left(s_{4}, 0.08\right)$ & $\left(s_{4}, 0.16\right)$ & $\left(s_{4}, 0.00\right)$ \\
\hline$A_{3}$ & $\left(s_{4}, 0.00\right)$ & $\left(s_{4}, 0.06\right)$ & $\left(s_{4}, 0.16\right)$ & $\left(s_{5}, 0.00\right)$ & $\left(s_{4}, 0.06\right)$ \\
\hline$A_{4}$ & $\left(s_{2}, 0.08\right)$ & $\left(s_{3}, 0.08\right)$ & $\left(s_{5}, 0.16\right)$ & $\left(s_{4}, 0.16\right)$ & $\left(s_{2}, 0.08\right)$ \\
\hline$A_{5}$ & $\left(s_{3}, 0.00\right)$ & $\left(s_{4}, 0.00\right)$ & $\left(s_{3}, 0.16\right)$ & $\left(s_{5}, 0.00\right)$ & $\left(s_{4}, 0.00\right)$ \\
\hline
\end{tabular}


Then we determine the binary semantic positive ideal solution and the binary semantic positive ideal solution.

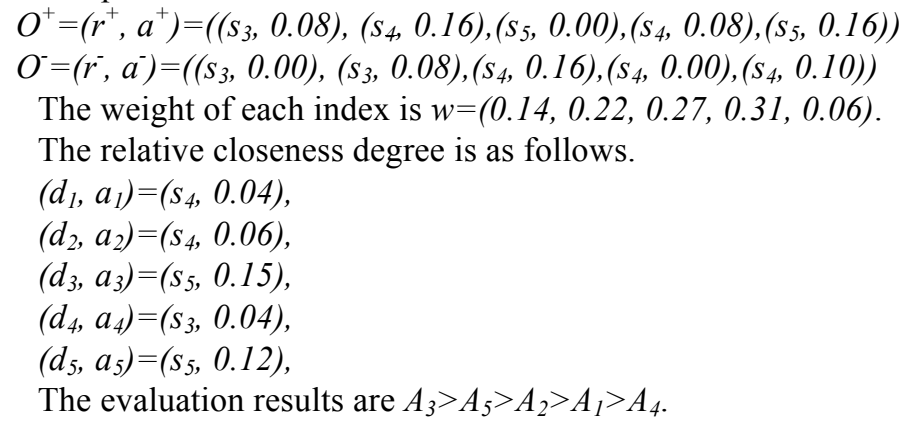

\section{Conclusions}

Colleges and universities are the place to train high quality talents. Through higher education, colleges transport many talents for the community. Evaluating the teaching quality of the higher education can improve the teaching level of the higher school. This paper applies the improved Grey-TOPSIS method to evaluate the teaching quality of the higher education. This paper contains the following works. Firstly, this paper introduces the Grey correlation model. Secondly, this paper proposes the improved Grey-TOPSIS method. Thirdly, this paper applies the improved Grey-TOPSIS method to evaluate the teaching quality of the higher education. The experimental results demonstrate the validity and the reliability of the method.

Evaluating the college strength comprehensively can not only guide the college to the scientific development, but also guide the students to select the colleges. According to the comprehensive evaluation, each college can improve the teaching quality, improve the level of talent training and promote the development of themselves. According to the comprehensive evaluation, the candidates and their parents can select better college and more suitable major. Based on this, this paper proposes the improved fuzzy TOPSIS method to evaluate the college comprehensively. The major contents of this paper are as follows. Firstly, this paper briefly introduces the present situation of the college comprehensive evaluation. Secondly, based on the fuzzy theory and TOPSIS method, this paper proposes the improved fuzzy TOPSIS method. Thirdly, this paper applies the improved fuzzy TOPSIS method to evaluate the college comprehensively. Finally, the experiment verifies the reliability and the validity of the method.

\section{References}

[1] Bergsmann, E., Schultes, M.T., Winter, P., Schober, B., Spiel, C. (2015). Evaluation of competence-based teaching in higher education: From theory to practice. Evaluation and Program Planning, 52: 1-9. https://doi.org/10.1016/j.evalprogplan.2015.03.001 
Paper-Research on the Comprehensive Strength Evaluation for Universities based on the Fuzzy...

[2] Peng, R.Z., Wu, W.P., Fan, W.W. (2015). A comprehensive evaluation of Chinese college students' intercultural competence. International Journal of Intercultural Relations, 47: 143-157. https://doi.org/10.1016/j.ijintrel.2015.04.003

[3] Yin, Z.M. (2005). Research on the indicator system of college integrated evaluation in China. Wuhan University, Information management.

[4] Xu, M. (2010). Research on the evaluation of university knowledge management. Harbin Institute of Technology, Management science and Engineering.

[5] Li, B.F. (2011). Application of fuzzy comprehensive evaluation method based on set valued iteration in comprehensive strength evaluation of University. Science \& Technology information, 21: 580-582.

[6] Huang, Q.S. (2007). Research on evaluation of universities comprehensive strength in Guangxi. Guangxi Normal University, Higher education management.

[7] Wang, X.Y. (2010). Research on higher schools teaching evaluation method based on comprehensive fuzzy judgment. Journal of Bohai University, 9: 300-304.

[8] Li, W.X., Qi, D.L., Zheng, S.F., Ren, J.C., Li, J.F., Yin, X. (2015). Fuzzy mathematics model and its numerical method of stability analysis on rock slope of opencast metal mine. Applied Mathematical Modelling, 39: 1784-1793. https://doi.org/10.1016/j.apm.2014. $\underline{10.006}$

[9] Chatterjee, A., Mukherjee, S., Kar, S. (2014). Poverty Level of Households: A Multidimensional Approach Based on Fuzzy Mathematics. Fuzzy Information and Engineering, 6: 463-487. https://doi.org/10.1016/j.fiae.2015.01.005

[10] Hüllermeier, E. (2015). Does machine learning need fuzzy logic? Fuzzy Sets and Systems, 281: 292-299. https://doi.org/10.1016/j.fss.2015.09.001

[11] Godo, L., Gottwald, S. (2015). Fuzzy sets and formal logics. Fuzzy Sets and Systems, 281: 44-60. https://doi.org/10.1016/j.fss.2015.06.021

[12] Gao, Y.B., Li, H.Y., Wu, L.G., Karimi, H., Lam, H. (2016). Optimal control of discretetime interval type-2 fuzzy-model-based systems with -stability constraint and control saturation. Signal Processing, 120: 409-421. https://doi.org/10.1016/j.sigpro.2015.09.007

[13] Ulu, C. (2015). Exact analytical inversion of interval type-2 TSK fuzzy logic systems with closed form inference methods. Applied Soft Computing, 37: 60-70. https://doi.org/10.1016/j.asoc.2015.08.013

[14] Chang, W., Hsu, F.L. (2016). Sliding mode fuzzy control for Takagi-Sugeno fuzzy systems with bilinear consequent part subject to multiple constraints. Information Sciences, 327(10): 258-271. https://doi.org/10.1016/j.ins.2015.08.026

[15] Zhang, J., Li, X.M., Zhao, T.Y., Dai, W. (2015). Experimental study on a novel fuzzy control method for static pressure reset based on the maximum damper position feedback. Energy and Buildings, 108: 215-222. https://doi.org/10.1016/j.enbuild.2015.09.014

[16] Chen, S.M., Cheng, S.H., Chiou, C.H. (2016). Fuzzy multiattribute group decision making based on intuitionistic fuzzy sets and evidential reasoning methodology. Information Fusion, 27: 215-227. https://doi.org/10.1016/j.inffus.2015.03.002

[17] Xu, Z., Zhao, N. (2016). Information fusion for intuitionistic fuzzy decision making: An overview. Information Fusion, 28: 10-23. https://doi.org/10.1016/j.inffus.2015.07.001

[18] Aghajani, M.M., Taherei, G.P., Sulaiman, N.M.N., Basri, N.E.A., Saheri, S., Mahmood, N.Z., Jahan, A., Begum, R.A., Aghamohammadi, N. (2016). Application of TOPSIS and VIKOR improved versions in a multi criteria decision analysis to develop an optimized municipal solid waste management model. Journal of Environmental Management, 166(9): 109-115. https://doi.org/10.1016/j.jenvman.2015.09.028 
Paper-Research on the Comprehensive Strength Evaluation for Universities based on the Fuzzy...

[19] Bilbao-Terol, A., Arenas-Parra, M., Cañal-Fernández, V., Antomil-Ibias, J. (2014). Using TOPSIS for assessing the sustainability of government bond funds. Omega, 49: 1-17. https://doi.org/10.1016/j.omega.2014.04.005

[20] Wanke, P., Barros, C., Macanda, N.P.J. (2016). Predicting Efficiency in Angolan Banks: A Two Stage TOPSIS and Neural Networks Approach. Research in International Business and Finance, 36(3): 485-498. https://doi.org/10.1016/j.ribaf.2015.10.002

[21] Oztaysi, B. (2014). A decision model for information technology selection using AHP integrated TOPSIS-Grey: The case of content management systems. Knowledge-Based Systems, 70: 44-54, https://doi.org/10.1016/j.knosys.2014.02.010

[22] Huang, W., Huang, Y.Y. (2012). Research on the Performance Evaluation of Chongqing Electric Power Supply Bureaus Based on TOPSIS. Energy Procedia, 14: 899-905. https://doi.org/10.1016/j.egypro.2011.12.1030

[23] Choudhary, D., Shankar, R. (2012). An STEEP-fuzzy AHP-TOPSIS framework for evaluation and selection of thermal power plant location: A case study from India. Energy, 42: 510-521. https://doi.org/10.1016/j.energy.2012.03.010

[24] Guo, S., Zhao, H.R. (2015). Optimal site selection of electric vehicle charging station by using fuzzy TOPSIS based on sustainability perspective. Applied Energy, 158: 390-402. https://doi.org/10.1016/j.apenergy.2015.08.082

[25] Aloini, D., Dulmin, R., Mininno, V. (2014). A peer IF-TOPSIS based decision support system for packaging machine selection. Expert Systems with Applications, 41: 21572165. https://doi.org/10.1016/j.eswa.2013.09.014

\section{$7 \quad$ Author}

Fuqin Yue received the master degree from Xi'an Jiao Tong University. Her research is mainly on investment and financing management; engaged in finance and investment research and teaching(yuefuqin@126.com).

Article submitted 13 May 2017. Published as resubmitted by the author 17 June 2017. 